Available online at http://journal.stkip-andi-matappa.ac.id/index.php/histogram/index

Histogram : Jurnal Pendidikan Matematika ., 2019, 228 - 239

\title{
PENGEMBANGAN LEMBAR KERJA SISWA (LKS) BERBASIS ICARE PADA MATA PELAJARAN MATEMATIKA SISWA
}

\author{
Suryanti $^{1^{*}}$, Muh. Asrullah ${ }^{2}$ \\ ${ }^{1,2}$ Universitas Pancasakti \\ * Corresponding Author. Email: anthysuryanti43@gmail.com \\ Received: 25 Juli 2019; Revised: 18 Agustus 2019 ; Accepted: 30 September 2019
}

\begin{abstract}
ABSTRAK
Secara rinci tujuan penelitian ini adalah (1) untuk mengetahui dan mendiskripsikan kualitas LKS berbasis ICARE pada materi Trigonometri ditinjau dari segi kevalidan, efektifitas dan kepraktisan. Jenis penelitian ini adalah metode pengembangan (Research and Development) melalui model ADDIE (analysis, design, development, implementasion, evaluation) yang melibatkan 2 orang guru matematika dan 10 orang siswa, pada uji coba pemakaian yang menjadi subjek uji coba adalah satu kelas. Instrumen penelitian yaitu instrumen validasi produk dari segi materi dan desain, instrumen persepsi guru dan siswa untuk mengetahui efektifitas LKS, instrumen observasi dan tes pilihan ganda dengan empat alternative pilihan jawaban. Untuk instrumen tes pilihan ganda dilakukan uji coba terlebih dahulu agar tes yang digunakan berkualitas kemudian dilakukan analisis item. Analisis ini digunakan untuk mengetahui validitas, daya pembeda, indeks kesukaran dan realibilitas. Hasil penelitian ini: (1) Lembar Kerja Siswa berbasis ICARE pada materi persamaan trigonometri memiliki kualitas baik karena telah memenuhi 3 aspek yaitu valid, efektif dan praktis.

Kata Kunci: Pengembangan, LKS, ICARE, Matematika.

How to Cite: Suryanti., \& Asrullah, M. (2019). Pengembangan Lembar Kerja Siswa (LKS) Berbasis Icare Pada Mata Pelajaran Matematika Siswa. Histogram: Jurnal Pendidikan Matematika, 3(2), 228 - 239 , doi: http://dx.doi.org/10.31100/histogram.v3i2.487

Permalink/DOI: http://dx.doi.org/10.31100/histogram.v3i2.487
\end{abstract}

\section{PENDAHULUAN}

Pendidikan matematika memiliki peran yang sangat penting karena matematika adalah ilmu dasar yang digunakan secara luas dalam berbagai bidang kehidupan. Melalui pembelajaran matematika siswa diharapkan dapat menumbuhkan kemampuan berpikir kritis, logis, sistematis, cermat, efektif, dan efisien dalam memecahkan masalah.

Dalam pembelajaran matematika, siswa sebaiknya dibiasakan untuk mendapatkan pemahaman dari pengalaman melalui proses mengidentifikasi sifat sifat yang dimiliki dan tidak dimiliki dari suatu objek matematis. Dengan adanya hal ini, dalam pembelajaran matematika di sekolah, guru hendaknya dapat memilih dan menggunakan strategi,

This is open access article under the CC-BY-SA-license. 


\section{Histogram: Jurnal Pendidikan Matematika, 3 (2), 2019 - 229 Suryanti, Muh. Asrullah}

pendekatan, metode dan media yang banyak melibatkan siswa dalam belajar, baik secara mental, fisik maupun sosial sehingga tercipta pembelajaran matematika yang aktif dan kreatif serta mandiri. Terkait dengan menciptakan pembelajaran matematika yang aktif dan kreatif serta mandiri, kehadiran perangkat pembelajaran sangatlah penting sebagai pendukung proses pembelajaran. Dengan adanya perangkat pembelajaran yang baik akan membantu guru beserta siswa untuk mencapai tujuan pembelajaran secara runtut dan sistematis.

Bahan ajar merupakan seperangkat materi yang disusun secara sistematis sehingga tercipta lingkungan atau suasana yang memungkinkan siswa untuk belajar serta digunakan dalam proses pembelajaran dengan tujuan perencanaan dan penelaahan implementasi pembelajaran (Prastowo, 2008). Bahan ajar dalam proses pembelajaran matematika disekolah dapat berupa buku pelajaran, modul dan Lembar Kerja Siswa (LKS). Siswa diharapkan belajar mandiri dengan menggunakan dan memanfaatkan bahan ajar yang telah disediakan, salah satunya yaitu LKS yang merupakan panduan kerja siswa untuk mempermudah siswa dalam pelaksanaan kegiatan pembelajaran matematika yang terdapat materi singkat dan soal-soal latihan agar dapat mengaktifkan siswa dalam proses pembelajaran dan meningkatkan kualitas hasil belajar.

Saat ini, LKS yang digunakan dalam pembelajaran matematika masih terdapat banyak kekurangan. Kebanyakan LKS yang ada hanya menekankan pada rumus tanpa menunjukkan cara penemuan dari rumus tersebut dan tidak memberikan kesempatan siswa untuk dapat menemukan konsep dari suatu materi secara mandiri sehingga terkesan LKS adalah suatu ringkasan materi dan kumpulan soal (Fannie, R. D., \& Rohati, 2014). LKS yang seperti itu akan dapat mengurangi kompetensi siswa dalam menalar pembelajaran khususnya pembelajaran matematika adalah untuk dapat membantu siswa dalam meningkatkan kemampuan penalaran dan penafsiran masalah matematika. Oleh karena itu, maka perlu dikembangkan LKS yang dapat meningkatkan keaktifan dan kemandirian siswa sehingga siswa merasa tertantang untuk melakukan suatu pemecahan masalah. atau menafsirkan suatu permasalahan yang ada.

Seiring dengan pengembangan LKS yang harus dilakukan oleh setiap pendidik, pemilihan metode pembelajaran disetiap kegiatan belajar haruslah tepat. Metode pembelajaran harus mampu menciptakan suatu interaksi secara aktif antara siswa dengan siswa maupun siswa dengan objek belajar sehingga dapat membuat siswa secara mandiri menemukan konsep dari materi yang diajarkan. Selain itu, metode pembelajaran yang 


\section{Histogram: Jurnal Pendidikan Matematika, 3 (2), 2019 - 230 Suryanti, Muh. Asrullah}

digunakan juga harus dapat membuat siswa merasa tertantang untuk mengikuti kegiatan belajar. Salah satu metode pembelajaran yang dapat dipilih dan dikembangkan oleh guru adalah model pembelajaran ICARE (Intreduction, Connection, Application, Reflection, Extension).

ICARE merupakan singkatan dari Introduction (pengenalan), Connect (menghubungkan), Apply (menerapkan dan mempraktikkan), Reflect (merefleksikan), dan Extend (memperluas dan evaluasi). ICARE pertama kali diperkenalkan oleh Bob Hoffman dan Donn Ritchie pada tahun 1997 di San Diego State University. Pada tahun 2006 United Stated Agency Internasional Development (USAID) Indonesia melalui program Decentralized Basic Education (DBE3) mengembangkan dan menperkenalkan ICARE pada pelatihan guru (Yumiati, Y., \& Wahyuningrum, 2015): (1). Introduction (Pendahuluan), Pada tahap pengalaman pembelajaran ini, para guru atau fasilitator menanamkan pemahaman tentang isi dari pelajaran kepada para peserta. Bagian ini harus berisi penjelasan tujuan pelajaran/sesi dan apa yang akan dicapai-hasil selama pelajaran/sesi tersebut. Introduction (pendahuluan) harus singkat dan sederhana; (2) Connection (penghubung), Sebagian besar pembelajaran merupakan rangkaian dengan satu kompetensi yang dikembangkan berdasarkan kompetensi sebelumnya. Oleh karena itu, semua pengalaman pembelajaran yang baik perlu dimulai dari apa yang sudah diketahui, dapat dilakukan oleh peserta, dan mengembangkannya. Pada tahap Connection dari pelajaran, anda berusaha menghubungkan bahan ajar yang baru dengan sesuatu yang sudah dikenal para peserta dari pembelajaran atau pengalaman sebelumnya. Anda dapat melakukan hal ini dengan mengadakan latihan brainstorming yang sederhana untuk memahami apa yang telah diketahui para peserta, dengan meminta mereka untuk memberitahu anda apa yang mereka ingat dari pelajaran/sesi sebelumnya atau dengan mengembangkan sebuah kegiatan yang dapat dilakukan peserta sendiri. Sesudah itu, anda dapat menghubungkan para peserta dengan informasi baru. Ini dapat dilakukan melalui presentasi atau penjelasan yang sederhana. Akan tetapi, perlu diingat bahwa presentasi seharusnya tidak terlalu lama dan paling lama hanya berlangsung selama sepuluh menit; (3) Application (penerapan), Tahap ini adalah tahap yang paling penting dari pelajaran. Setelah peserta memperoleh informasi atau kecakapan baru melalui tahap Connection, mereka perlu diberi kesempatan untuk mempraktikkan dan menerapkan pengetahuan serta kecakapan tersebut. Bagian Application harus berlangsung paling lama dari pelajaran di mana peserta bekerja sendiri, tidak dengan instruktur, secara pasangan atau dalam 


\section{Histogram: Jurnal Pendidikan Matematika, 3 (2), 2019 - 231 \\ Suryanti, Muh. Asrullah}

kelompok untuk menyelesaikan kegiatan nyata atau memecahkan masalah nyata menggunakan informasi dan kecakapan baru yang telah mereka peroleh; (4) Reflection (Refleksi), Bagian ini merupakan ringkasan dari pelajaran, sedangkan peserta memiliki kesempatan untuk merefleksikan apa yang telah mereka pelajari. Tugas guru adalah menilai sejauh mana keberhasilan pembelajaran. Kegiatan refleksi atau ringkasan dapat melibatkan diskusi kelompok dimana instruktur meminta peserta untuk melakukan presentasi atau menjelaskan apa yang telah siswa pelajari. Siswa juga dapat melakukan kegiatan penulisan mandiri dimana peserta menulis sebuah ringkasan dari hasil pembelajaran. Refleksi ini juga bisa berbentuk kuis singkat dimana instruktur memberi pertanyaan berdasarkan isi pelajaran. Poin penting untuk diingat dalam refleksi adalah instruktur perlu menyediakan kesempatan bagi para peserta untuk mengungkapkan apa yang telah mereka pelajari; (5) Extension (perluasan/pengembangan), Karena waktu pelajaran/sesi telah selesai, bukan berarti semua peserta yang telah mempelajari dapat secara otomatis menggunakan apa yang telah mereka pelajari. Kegiatan bagian Extension adalah kegiatan dimana guru menyediakan kegiatan yang dapat dilakukan peserta setelah pelajaran berakhir untuk memperkuat dan memperluas pembelajaran. Di sekolah, kegiatan Extension biasanya disebut pekerjaan rumah. Kegiatan Extension dapat meliputi penyediaan bahan bacaan tambahan, tugas penelitian atau latihan.

Maka peneliti tertarik untuk mengadakan penelitian tentang pengembangan LKS berbasis ICARE pada materi Trigonometri. Berdasarkan latar belakang yang telah dikemukakan di atas, maka tujuan penelitian ini adalah untuk mengetahui: "Bagaimana kualitas LKS berbasis ICARE pada materi Trigonometri ditinjau dari segi kevalidan, efektifitas dan kepraktisan.".

\section{METODE PENELITIAN}

Metode penelitian yang digunakan dalam penelitian ini adalah metode pengembangan (Research and Development). (Sugiyono, 2013) menjelaskan bahwa penelitian dan pengembangan adalah penelitian yang digunakan untuk menghasilkan produk tertentu dan menguji keefektifan produk tersebut. Penelitian ini dikatakan penelitian pengembangan karena menghasilkan sebuah bahan ajar cetak yang berupa lembar kerja siswa (LKS) berbasis ICARE (Intreduction, Connection, Application, Reflection, Extension) yang kemudian akan di uji validitas dan keefektifannya. 


\section{Histogram: Jurnal Pendidikan Matematika, 3 (2), 2019 - 232 Suryanti, Muh. Asrullah}

\section{A. Prosedur Pengembangan}

Penelitian ini bertujuan untuk mengembangkan sebuah LKS pada materi Trigonometri dan meningkatkan prestasi belajar peserta didik. Tahap ini peneliti mendesain LKS berbasis ICARE (Intreduction, Connection, Application, Reflection, Extension). Desain LKS sesuai dengan apa yang menjadi kompetensi yang akan di capai siswa. Langkah-langkah dalam membuat LKS pembelajaran matematika berbasis ICARE (Intreduction, Connection, Application, Reflection, Extension)) pada materi Trigonometri adalah sebagai berikut:

1. Menentukan judul LKS

2. Pengumpulan Referensi

3. Penulisan LKS

4. Mencetak Lembar Kerja Siswa matematika berbasis ICARE (Intreduction, Connection, Application, Reflection, Extension)

\section{B. Subjek Uji Coba}

Dalam uji coba produk, yang menjadi subjek adalah 2 orang guru matematika dan 10 orang siswa. Pada uji coba pemakaian yang menjadi subjek uji coba adalah satu kelas yaitu siswa kelas XI SMA Negeri 17 Kota Makassar.

\section{Instrumen Pengumpulan Data}

Instrumen penelitian adalah suatu alat yang digunakan mengukur fenomena alam maupun sosial yang diamati (Sugiyono, 2013). Instrumen dalam penelitian ini adalah instrumen persepsi guru dan siswa untuk mengetahui efektifitas LKS, dan tes hasil belajar siswa untuk mengetahui ketuntasan belajar siswa.

\section{Teknik Analisis Data}

Teknik yang digunakan dalam penelitian ini adalah teknik pengembangan menurut langkah-langkah pengembangan ADDIE dengan tahapan sebagai berikut:

1. Mengumpulkan informasi untuk pembuatan LKS berbasis ICARE (Intreduction, Connection, Application, Reflection, Extension) pada materi Trigonometri.

2. Membuat desain LKS berbasis ICARE (Intreduction, Connection, Application, Reflection, Extension) pada materi Trigonometri.

3. Desain yang telah dibuat selanjutnya divalidasi oleh tenaga ahli materi berdasarkan validasi isi, konstruk, dan bahasa serta tenaga ahli desain media pembelajaran. Jika ditemukan suatu kelemahan dan kekurangan pada LKS tersebut, maka desain tersebut harus direvisi kembali berdasarkan saran validator. 


\section{Histogram: Jurnal Pendidikan Matematika, 3 (2), 2019 - 233 Suryanti, Muh. Asrullah}

4. Setelah merevisi desain tersebut, maka dilakukan uji coba produk terbatas. Ujicoba dilaksanakan pada 2 orang guru mata pelajaran matematika dan kepada 10 orang siswa kelas XI SMA Negeri 17 kota Makassar. Uji coba ini dilakukan untuk melihat tanggapan dan penilaian dari guru dan siswa tentang manfaat penggunaan LKS yang telah dibuat, kemudian akan dilakukan revisi sesuai dengan data angket pada uji coba produk.

5. Setelah dilakukan revisi, maka dilakukanlah uji coba pemakaian untuk keadaan sesungguhnya (dalam pembelajaran) pada satu kelas. Pada tahap uji coba pemakaian ini angket respon siswa untuk melihat kepraktisan siswa dalam belajar menggunakan LKS berbasis ICARE (Intreduction, Connection, Application, Reflection, Extension). Lembar respon siswa tersebut terdiri dari 12 pertanyaan tertutup dengan menggunakan skala likert. Berikutnya dilakukan analisis dengan perhitungan sebagai berikut:

$$
\text { Jumlah skor indikator }=\frac{\text { jumlah skor aspek yang tampak }}{\text { jumlah responden }} \times 100 \% \text {......(1) }
$$

6. Setelah siswa diajarkan dengan menggunakan LKS tersebut kemudian dilakukan posttest pada satu kelas untuk melihat manfaat penggunaan LKS pada hasil belajar siswa tersebut. Post-test yang dilakukan berpatok pada KKM yaitu 76 dengan standar ketuntasan kelas yaitu 70\%. Adapun rumus yang digunakan adalah sebagai berikut:

$$
P=\frac{m}{n} \times 100 \%
$$

Keterangan:

$\mathrm{P}=$ persentase nilai siswa yang sesuai KKM

$\mathrm{m}=$ banyak siswa yang nilainya sesuai $\mathrm{KKM}$

$\mathrm{n}=$ banyaknya siswa

\section{HASIL DAN PEMBAHASAN}

\section{A. Hasil Penelitian}

Langkah-langkah pengembangan bahan ajar sesuai dengan model pengembangan ADDIE sebagai berikut (Hamimi, L., Ikhsan, M., \& Abidin, 2018) :

1. Analysis (Analisis)

Pada tahap ini dilakukan analisis kebutuhan dan karakteristik siswa. Analisis kebutuhan meliputi analisis kurikulum pada materi persamaan trigonometri. Analisis 


\section{Histogram: Jurnal Pendidikan Matematika, 3 (2), 2019 - 234 Suryanti, Muh. Asrullah}

kebutuhan merupakan langkah yang diperlukan untuk menentukan kemampuan atau kompetensi yang perlu dipelajari oleh siswa untuk meningkatkan prestasi belajar.

Analisis karakteristik siswa dilakukan melalui wawancara dengan guru matematika. Berdasarkan hasil wawancara dengan guru, dapat disimpulkan sebagai berikut:

a. Kurangnya kemampuan dan semangat siswa dalam belajar matematika, dilihat dari antusias dan keaktifan siswa dalam pembelajaran.

b. Belum adanya Lembar Kerja Siswa (LKS), sehingga siswa hanya mengerjakan latihan-latihan soal yang ada di buku. Oleh karena itu, peneliti ingin mengembangkan LKS yang sesuai dengan kebutuhan yang diharapkan siswa.

c. Masih banyak siswa yang kurang paham dengan materi trigonometri, sehingga nilai ulangan hariannya masih banyak yang di bawah KKM,

2. Design (desain)

Setelah dilakukan analisis kebutuhan langkah selanjutnya adalah merancang/membuat Lembar Kerja Siswa (LKS) berbasis ICARE. LKS ini disusun berdasarkan kompetensi dasar dan indikator yang ingi dicapai pada materi persamaan trigonometri.

3. Development (Pengembangan)

Lembar Kerja Siswa (LKS) yang telah selesai kemudian di validasi oleh dua orang yang terdiri dari Marawati, S.Pd. dan Surianti, S.Si. menyatakan bahwa LKS berbasis ICARE dapat digunakan untuk penelitian karena telah memenuhi kriteria valid.

\section{Implementation (Implementasi)}

Tahap ini merupakan tahap dari pengembangan. Setelah instrumen divalidasi, peneliti melakukan uji coba kepada 10 orang siswa kelas XI, untuk melihat respon/masukan dari siswa terhadap LKS berbasis ICARE yang telah dikembangkan.

Tabel 1. Analisis Respon Siswa

\begin{tabular}{ccc}
\hline No & Pertanyaan & Rata-rata Skor \\
\hline 1 & $\begin{array}{l}\text { Lembar kegiatan siswa (LKS) } \\
\text { yang mudah dipahami }\end{array}$ & 3,47 \\
\hline
\end{tabular}


Histogram: Jurnal Pendidikan Matematika, 3 (2), 2019 - 235

Suryanti, Muh. Asrullah

\begin{tabular}{|c|c|c|}
\hline No & Pertanyaan & Rata-rata Skor \\
\hline 2 & $\begin{array}{l}\text { LKS menggunakan kalimat yang tidak menimbulkan } \\
\text { makna ganda }\end{array}$ & 3,57 \\
\hline 3 & $\begin{array}{l}\text { Petunjuk kegiatan dalam LKS jelas, sehingga } \\
\text { mempermudah saya dalam melakukan semua kegiatan }\end{array}$ & 3,6 \\
\hline 4 & $\begin{array}{l}\text { Pemilihan jenis huruf, ukuran serta spasi yang } \\
\text { digunakan mempermudah saya dalam membaca LKS }\end{array}$ & 3,47 \\
\hline 5 & $\begin{array}{l}\text { Pada awal pembelajaran menggunakan lembar kerja } \\
\text { siswa ini, ada sesuatu yang menarik bagi saya }\end{array}$ & 3,57 \\
\hline 6 & $\begin{array}{l}\text { Ketika belajar saya selalu memeriksa kembali hasil } \\
\text { pekerjaan yang saya peroleh dan membuat kesimpulan } \\
\text { sesuai dengan masalah yang ditanyakan }\end{array}$ & 3,4 \\
\hline 7 & $\begin{array}{l}\text { Dari setiap kegiatan yang ada dalam LKS ini saya dapat } \\
\text { menyimpulkan dan mengambil ide-ide penting } \\
\text { mengenai materi persamaan trigonometri }\end{array}$ & 3,4 \\
\hline 8 & $\begin{array}{l}\text { Saya dapat menghubungkan isi LKS ini dengan hal-hal } \\
\text { yang telah saya lihat, saya lakukan, atau saya pikirkan } \\
\text { dalam kehidupan sehari-hari }\end{array}$ & 3,2 \\
\hline 9 & $\begin{array}{l}\text { Saya dapat memperoleh pengetahuan dengan mengikuti } \\
\text { serangkaian kegiatan dalam lembar kerja siswa }\end{array}$ & 3,33 \\
\hline 10 & Isi LKS ini sangat bermanfaat bagi saya & 3,4 \\
\hline 11 & $\begin{array}{l}\text { Saya senang mempelajari matematika khususnya } \\
\text { persamaan trigonometri menggunakan LKS ini }\end{array}$ & 3,63 \\
\hline 12 & Isi LKS ini sesuai dengan minat saya & 3,2 \\
\hline & Jumlah & 41,2 \\
\hline & Skor rata-rata & 3,44 \\
\hline
\end{tabular}

(Sumber: Data Primer, Tahun: 2019)

Berdasarkan tabel respon siswa untuk setiap pertanyaan berkisar antara setuju dan sangat setuju atau dapat dikatakan bahawa respon siswa terhadap LKS berbasis ICARE baik dan sangat baik. Berdasarkan nilai rata-rata keseluruhan diperoleh skor 3,44, maka dapat 
Histogram: Jurnal Pendidikan Matematika, 3 (2), 2019 - 236 Suryanti, Muh. Asrullah

disimpulkan respon siswa terhadap LKS berbasis ICARE sangat positif sehingga dapat dikatakan sangat praktis.

Penilaian pada penelitian ini dilakukan melalui tes hasil belajar secara tertulis dan dilaksanakan dalam satu tahap, yaitu tes dilaksanakan setelah diberikan pembelajaran dengan menggunakan LKS berbasis ICARE. Skor hasil belajar siswa dapat dilihat ari tabel berikut

Tabel 2. Tes Hasil Belajar Siswa

\begin{tabular}{|c|c|c|}
\hline Kode Siswa & Skor & Keterangan \\
\hline AA & 90 & Tuntas \\
\hline $\mathrm{AC}$ & 90 & Tuntas \\
\hline $\mathrm{AL}$ & 70 & Tidak Tuntas \\
\hline $\mathrm{AM}$ & 83 & Tuntas \\
\hline $\mathrm{AD}$ & 80 & Tuntas \\
\hline $\mathrm{AF}$ & 93 & Tuntas \\
\hline AY & 93 & Tuntas \\
\hline AS & 97 & Tuntas \\
\hline DA & 90 & Tuntas \\
\hline FA & 93 & Tuntas \\
\hline FP & 97 & Tuntas \\
\hline HA & 93 & Tuntas \\
\hline IN & 97 & Tuntas \\
\hline $\mathrm{JM}$ & 87 & Tuntas \\
\hline $\mathrm{MC}$ & 87 & Tuntas \\
\hline $\mathrm{MM}$ & 100 & Tuntas \\
\hline MR & 83 & Tuntas \\
\hline MT & 87 & Tuntas \\
\hline MR & 93 & Tuntas \\
\hline $\mathrm{NM}$ & 80 & Tuntas \\
\hline NB & 90 & Tuntas \\
\hline NI & 70 & Tidak Tuntas \\
\hline NR & 97 & Tuntas \\
\hline
\end{tabular}

Copyright (C) Tahun Terbit, Histogram: Jurnal Pendidikan Matematika ISSN: 2549-6700 (print), ISSN 2549-6719 (online) 
Histogram: Jurnal Pendidikan Matematika, 3 (2), 2019 - 237

Suryanti, Muh. Asrullah

\begin{tabular}{ccc}
\hline Kode Siswa & Skor & Keterangan \\
\hline NA & 80 & Tuntas \\
\hline NT & 63 & Tidak Tuntas \\
\hline OM & 100 & Tuntas \\
\hline SZ & 87 & Tuntas \\
\hline SN & 63 & Tidak Tuntas \\
\hline SR & 93 & Tuntas \\
\hline TN & 87 & Tuntas
\end{tabular}

(Sumber: Data Primer, Tahun: 2019)

$\mathrm{P}=$ Persentase ketuntasan siswa $=\frac{P a}{P b} \times 100 \%$

$P a=$ Jumlah siswa tuntas $=26$ siswa

$P b=$ Jumlah siswa keseluruhan $=30$ siswa

$P=\frac{P a}{P b} \times 100 \%$

$=\frac{26}{30} \times 100 \%$

$=86.67 \%$

Berdasarkan tabel di atas dapat diketahui bahwa 26 siswa (86.67\%) tuntas belajar, sedangkan 4 siswa (13.33\%) tidak tuntas belajarnya. Berdasarkan KKM pelajaran matematika di SMA negeri 17 Makassar, ketuntasan individu adalah 76 dan ketuntasan klasikal $86.67 \%$ dan hasil belajar menunjukkan bahwa LKS berbasis ICARE memiliki ketuntasan sangat tinggi sehingga dapat dikatakan sangat efektif.

5. Evaluatin (Evaluasi)

Pada tahan evaluasi dilakukan revisi terhadap LKS yang telah dikembangkan. Perbaikan dilakukan berdasarkan hasil pengamatan selama implementasi LKS berbasis ICARE di kelas dan beberapa saran dari siswa. Dari hasil revisi akhir, tersusunlah produk akhir berjudul Lembar Kerja Siswa (LKS) berbasis ICARE. Dari uraian di atas dapat disimpulkan LKS yang dikembangkan memiliki kualitas baik karena memenuhi 3 aspek yaitu valid, efektif dan praktis. 


\section{Histogram: Jurnal Pendidikan Matematika, 3 (2), 2019 - 238 Suryanti, Muh. Asrullah}

\section{B. Pembahasan}

LKS yang dikembangkan memiliki kualitas baik karena memenuhi 3 aspek yaitu valid, efektif dan praktis. Menurut (Fannie, R. D., \& Rohati, 2014), LKS yang berkualitas, maka LKS ini bermanfaat dan layak untuk digunakan dalam proses pembelajaran, dan dapat membantu siswa meningkatkan hasil pembelajaran.

Walaupun dalam pengembangan LKS ini belum terlalu memperlihatkan aspek ICARE akan tetapi siswa tetap tertarik dengan LKS tersebut. Menurut (Ernawati, A., Ibrahim, M, M., \& Afiif, 2017), ketika siswa sudah tertarik terhadap LKS maka akan membangkitkan motivasi siswa untuk belajar, menyediakan siswa untuk belajar sesuai dengan minat, bakat dan talentanya, meningkatkan kemampuan siswa dalam bidang yang mereka sukai, sampai dengan memberikan pengaruh positif dalam suasana belajar yang menyenangkan dan tidak membatasi siswa. Ditambah dengan bahan ajar yang disediakan seperti LKS akan sangat membantu siswa dalamproses pembelajaran. tidak hanya menjadikan susana belajar yang menyenangkan, tetapi juga mempermudah siswa dalam memahami materi yang disajikan. Siswa dapatmenyelesaikan masalah yang terdapat dalam pelajaran dengan kemampuan yang mereka miliki.

\section{KESIMPULAN DAN SARAN}

\section{A. Kesimpulan}

Berdasarkan dari hasil penelitian, dapat disimpulkan bahwa Lembar Kerja Siswa berbasis ICARE pada materi persamaan trigonometri dikembangkan melalui model ADDIE (analysis, design, development, implementasion, evaluation) memiliki kualitas baik karena telah memenuhi 3 aspek yaitu valid, efektif dan praktis. Walaupun dalam pengembangan Lembar Kerja Siswa ini belum terlalu memperlihatkan aspek ICARE akan tetapi siswa tetap tertarik dengan LKS tersebut.

\section{B. Saran}

Penulis dapat meyarankan untuk lebih banyak lagi penelitian tentang pengembangan bahan ajar seperti modul dan LKS, dikarenakan siswa pada zaman ini kurang memiliki inisiatif untuk membeli buku sendiri, jadi sebaiknya sebagai seorang guru yang kreatif lebih disarankan untuk membuat sendiri bahan ajar untuk siswa agar pembelajaran dapat terlaksana dengan lebih efektif. 


\section{DAFTAR PUSTAKA}

Ernawati, A., Ibrahim, M, M., \& Afiif, A. (2017). Pengembangan Lembar Kerja Siswa berbasis Multiple Intelligences Pada Pokok Bahasan Substansi Genetika Kelas XII IPA SMA Negeri 16 Makassar. Jurnal Biotek, 5(2), 1-18.

Fannie, R. D., \& Rohati, R. (2014). Pengembangan lembar kerja siswa (LKS) berbasis POE (predict, observe, explain) pada materi program linear kelas XII SMA. Sainmatika: Jurnal Sains Dan Matematika Universitas Jambi, 8(1), 96-109.

Hamimi, L., Ikhsan, M., \& Abidin, Z. (2018). Pengembangan perangkat pembelajaran pembuktian menggunakan model pembelajaran guided inquiry untuk meningkatkan kemampuan geometri siswa Sekolah Menengah Atas. Jurnal Didaktik Matematika, $5(1), 16-26$.

Prastowo, A. (2008). Panduan Kreatif Membuat Bahan Ajar Inovatif. Yogyakarta: Diva Press.

Sugiyono. (2013). Metode Penelitian Pendidikan Kuantitatif, Kualitatif, dan $R \& D$. Bandung: Alfabeta.

Yumiati, Y., \& Wahyuningrum, E. (2015). Pembelajaran ICARE (Inroduction, Connect, Apply, Reflect, Extend) Dalam Tutorial Online Untuk Meningkatkan Kemampuan Pemecahan Masalah Matematis Mahasiswa UT. Infinity Journal, 4(2), 182-189. 